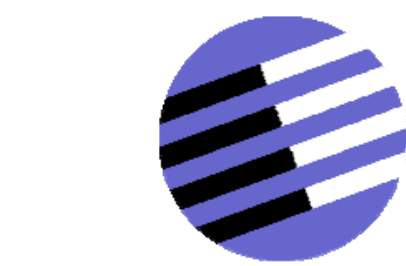

GOVERNANCE AND THE EFFICIENCY

OF ECONOMIC SYSTEMS

GESY

\begin{tabular}{|} 
Discussion Paper No. 220 \\
The Actual Structure of eBay's \\
Feedback Mechanism and Early \\
Evidence on the Effects of Recent \\
Changes \\
Tobias J. Klein* \\
Christian Lambertz** \\
Giancarlo Spagnolo*** \\
Konrad O. Stahl****
\end{tabular}

*Tobias J. Klein, Tilburg University, CentER, IZA, and netspar, T.J.Klein@uvt.nl

**Christian Lambertz, University of Mannheim, lambertz@econ.uni-mannheim.de

***Giancarlo Spagnolo, University of Rome "Tor Vergata", SITE - Stockholm School of Economics, C.E.P.R., ENCORE, giancaspagnolo@yahoo.com

****Konrad O. Stahl, University of Mannheim, C.E.P.R., CESifo, and ZEW, kos@econ.uni-mannheim.de

Financial support from the Deutsche Forschungsgemeinschaft through SFB/TR 15 is gratefully acknowledged.

Sonderforschungsbereich/Transregio $15 \cdot$ www.gesy.uni-mannheim.de

Universität Mannheim · Freie Universität Berlin · Humboldt-Universität zu Berlin · Ludwiq-Maximilians-Universität München Rheinische Friedrich-Wilhelms-Universität Bonn · Zentrum für Europäische Wirtschaftsforschung Mannheim 


\title{
The Actual Structure of eBay's Feedback Mechanism and Early Evidence on the Effects of Recent Changes ${ }^{1}$
}

\author{
Tobias J. Klein \\ Christian Lambertz \\ Giancarlo Spagnolo \\ Konrad O. Stahl ${ }^{2}$
}

November 6, 2007

\begin{abstract}
eBay's feedback mechanism is considered crucial to establishing and maintaining trust on the world's largest trading platform. The effects of a user's reputation on the probability of sale and on prices are at the center of a large number of studies. More recent theoretical work considers aspects of the mechanism itself. Yet, there is confusion amongst users about its exact institutional details, which also changed substantially in the last few months. An understanding of these details, and how the mechanism is perceived by users, is crucial for any assessment of the system. We provide a thorough description of the institutional setup of eBay's feedback mechanism, including recent changes to it. Most importantly, buyers now have the possibility to leave additional, anonymous ratings on sellers on four different criteria. We discuss the implications of these changes and provide first descriptive evidence on their impact on rating behavior.
\end{abstract}

JEL Classification: D44, L15, L86.

Keywords: eBay, reputation mechanism, strategic feedback behavior, informational content, reciprocity, fear of retaliation.

\footnotetext{
${ }^{1}$ We are grateful to Florian Hauber and Johannes Koenen for excellent research assistance and Heski Bar-Isaac, Ali Hortaçsu, Florian Müller, Axel Ockenfels, Klaus Schmidt, Henry Schneider, and Mike Ward for stimulating discussions and comments on related work.

${ }^{2}$ T. Klein (T.J.Klein@uvt.nl): Tilburg University, CentER, IZA; and netspar; C. Lambertz (lambertz@econ.unimannheim.de): University of Mannheim; K. Stahl (kos@econ.uni-mannheim.de): University of Mannheim, C.E.P.R., CESifo, and ZEW; G. Spagnolo (giancaspagnolo@yahoo.com): University of Rome 'Tor Vergata,' SITE - Stockholm School of Economics, C.E.P.R., ENCORE.
} 


\section{Introduction}

EBay is the largest market ever to exist in terms of number of participants. It brings together about 100 million private and professional buyers and sellers. In 2006, the number of listings exceeded 2.3 billion, and eBay's gross merchandise volume amounted to more than 52 billion U.S. dollars. ${ }^{3}$ This great success is often attributed to eBay’s feedback mechanism which is argued to foster trust in the platform (see e.g. Resnick and Zeckhauser 2002).

The feedback mechanism, which allows users to build a reputation on eBay, is claimed to be crucial because trading on electronic platforms involves a particularly wide room for opportunistic behavior on both sides of the market. Anonymity and distance allow sellers to cheat on the quality of the good. Likewise, buyers can be dishonest concerning their payment behavior. ${ }^{4}$ As long as feedback reflects the trading partners' experience in a transaction, accumulated feedback indeed provides valuable information for potential trading partners. Thereby, the feedback mechanism potentially disciplines the agents so that the aforementioned forms of opportunism are attenuated by the threat that, if an agent misbehaves today, she will receive a bad feedback and will therefore be avoided by other traders in the future. Public statements by eBay emphasize this (desired) effect of the feedback mechanism. ${ }^{5}$

On eBay, both the seller and the buyer of an object can rate each other after a transaction. It has been argued that this reciprocity might lead to strategic reciprocation and retaliation: Leaving a positive rating could be driven by expectations to receive a positive rating in return, while agents dissatisfied with their trading partners could refrain from leaving negative feedback at all, as they anticipate revenge. Both forms of behavior would bias the reputation index towards more positive evaluations. ${ }^{6}$

\footnotetext{
${ }^{3}$ See http://files.shareholder.com/downloads/ebay/98500789x0x69405/2cbacae7-15cf-46fb-9a19-a89664d4e591/ eBayIncEarningsReleaseQ42006.pdf (March 2007).

${ }^{4}$ According to the Internet Crime Complaint Center (IC3) 2005 Internet Fraud Crime Report "internet auction fraud was by far the most reported offense, comprising $62.7 \%$ of [97,076] referred complaints." See http://www.ic3.gov/media/annualreports.aspx (September 2006). Likewise, the FTC reports that "internet auction fraud is on the rise, with an increasing number of consumers complaining about sellers who deliver their advertised goods late or not at all, or deliver something far less valuable than promised.” See the FTC's “Top Ten Dot Cons” on http://www.ftc.gov/bcp/conline/edcams/ dotcon/auction.htm (February 2006).

${ }^{5}$ eBay states that the feedback "comments and ratings are valuable indicators of your reputation as a buyer or seller on eBay,” see http://pages.ebay.com/help/feedback/questions/feedback.html (February 2006). Moreover, in the founder's letter posted on February 26, 1996, Pierre Omidyar claims that "some people are dishonest. Or deceptive...But here, those people can’t hide. We'll drive them away.” See http://pages.ebay.com/services/ forum/feedback-foundersnote.html (February 2006).

${ }^{6}$ This tendency to reciprocate may be due to behavioral components in agents' decision making processes, similar to the ones found by Fehr and Schmidt (1999), the attempt to build up a reputation as a "reciprocator" or "impersonator" in order to discourage future negative ratings and encourage positive ones_- "the high courtesy equilibrium" of Resnick and Zeckhauser (2002)_, or the combination of both motives. Dellarocas and Wood (forthcoming) relate the motivation for leaving positive feedback to the user's expectation of reciprocal behavior by their trading partners. They estimate that only about 86 per cent of eBay users are actually happy with the
} 
The informational content of any user's feedback record depends on the incentives to report truthfully rather than strategically, that is, on the design of the feedback mechanism. For example, if feedback is reciprocal and traders are hesitant to report a bad transaction because they fear revenge from their trading partner, then a fixed length of the time period in which feedback can be left would allow for leaving a negative rating in the very last moment of this period. By "sniping” negative feedback - i.e., leaving it so late that the other party cannot react any more - users would be safe from retaliation.

Retaliating against deserved negative feedback and reciprocating positive ratings may be used to build a reputation of being an imitator who always replies strategically to a positive feedback with a positive one, and to a negative feedback with a negative one. Such behavior is in principle observable to other users on $\mathrm{eBay}^{7}$, and to be known as an imitator may be valuable, for example, for a seller after she has received payment because it encourages her trading partner to give a positive feedback and discourages him from giving a negative one. ${ }^{8}$ EBay even sells a service to sellers allowing them to automatically reciprocate positive feedback. ${ }^{9}$

The fear of retaliatory negative feedback is regularly expressed in discussion boards and newsgroups on eBay, and users indeed seem to be hesitant to leave negative first ratings. Statements similar to the following from a buyer can be found in many forums ${ }^{10}$ :

In the past I've not left any neg[ative] feedback as I'm afraid of revenge feedback that'll paint me as a bad trading partner...the dodgy seller ends up with getting away with it just to rip someone else off.

The idea to leave negative ratings so late that the other party cannot react is often put forward to solve the dilemma ${ }^{11}$ :

\footnotetext{
underlying transaction.

${ }^{7}$ In particular, the feedback a user gets and the replies she leaves can be inferred from her feedback record.

${ }^{8}$ At the same time, if potential trading partners are fully aware of this, some of them will probably abstain from participating in the auction, knowing that a negative first feedback would always be retaliated.

${ }_{9}$ The price for an online seller tool which includes this service is currently $\$ 15.99$ a month, see http://pages.ebay.com/sell/automation.html (February 2006) for a description.

10 Quote taken from http://ideas.4brad.com/archives/000018.html (February 2006). See the newsgroup discussions on http://www.the-gas-station.com/messages.cfm?type=normal\&thread_id=49933\&lastdays=2000\& and http:// community.auctionsniper.com/groupee/forums/a/tpc/f/785608021/m/308108399/r/3721016131, for example (February 2006).

${ }^{11}$ Quote from http://www.the-gas-station.com/messages.cfm?type=normal\&thread_id=49933\&lastdays=2000\& (February 2006).
} 
The secret...is to wait until the 90 day feedback period is nearly up and then zap em w[ith a] negative feedback when they only have a few hours remaining to respond...That way they can't retaliate...This only wor[ks] if you are able to hold a grudge for 90 days...

Accordingly, McDonald and Slawson (2002) note that "some users attempt to avoid retaliatory negative feedback by 'sniping a negative' ”. Auctionhawk, a company specialized on offering services around eBay, even developed and advertised a service, for payment, to give feedback in the last minute. ${ }^{12}$ One contribution of this paper is to show that "feedback sniping” is in fact technically impossible on eBay, as will be explained below.

Reputation is of central importance in electronic markets. The functioning of a feedback mechanism depends on its design. In this paper, rather than focusing on the effects of reputation, for example on prices or the probability of selling, we provide detailed information on the precise design of the feedback mechanism on eBay, on which it appears to be there substantial confusion, and on how it just changed. ${ }^{13}$ Important characteristics are the sequential nature of the feedback giving, the ending rule for the time feedback can be left, the possibility to mutually withdraw ratings, and the additional, anonymous seller ratings that can now be left by buyers.

Until the end of April 2007, a user's reputation on eBay consisted of all ratings received from his trading partners, buyers or sellers, on past transactions. In May 2007 the system changed. Since then, buyers have the possibility to leave additional ratings on sellers, one to five stars, reflecting their satisfaction with the accuracy of the auction listing, communication, shipping speed and shipping charges. These ratings can be left anonymously and are summarized in additional summary statistics. After describing the change, we provide descriptive evidence that is obtained from recently collected data. The results suggest that the recent changes are a useful means to increase the amount of dissatisfaction that is communicated to the community.

\footnotetext{
12 See http://auctionbytes.com/cab/abn/y04/m08/i10/s01 (February 2006). A free reminder service for "last minute feedback" is offered by U.K. Auction Watch at http://www.ukauctionhelp.co.uk/remindme.php (February 2006).

${ }^{13}$ See Dellarocas (2005) for a useful survey of recent research on reputation mechanisms, and Dellarocas, Dini, and Spagnolo (2006) for a practical guidance to their design. The effects of seller reputation on prices and the probability of selling the object are usually found to be negligible or positive. See, for example, Melnik and Alm (2002), Bajari and Hortaçsu (2003), Cabral and Hortaçsu (2006), Livingston and Evans (2004), Lucking-Reiley, Bryan, Prasad, and Reeves (2007), Houser and Wooders (2006). See also Bajari and Hortaçsu (2004) as well as Resnick, Zeckhauser, Swanson, and Lockwood (2004) for an overview.
} 
The remainder of the paper unfolds as follows. Section 2 gives a detailed analysis of the "classic" part of the feedback mechanism. Section 3 describes the recent changes to the system and the newly introduced reputation measures. In section 4 we provide first empirical evidence on the effect of these changes. We conclude in Section 5, suggesting additional simple ways to discourage opportunistic feedback giving, and to improve on agents' incentives to truly express their satisfaction or dissatisfaction on eBay.

\section{The ‘Classic’ eBay Feedback Mechanism}

When an auction ends or an item is sold, eBay sends a notification to the seller and the buyer who should then contact each other and arrange payment and shipping. As an intermediary, eBay assumes no responsibility in the process after the auction has ended, and only gets involved if a dispute arises.

As soon as the auction is over (or the item is sold, if not through an auction), both the seller and the buyer can leave feedback on their trading partner regarding this transaction. Neither party is required to leave feedback, but is actively encouraged by eBay to do so. Resnick and Zeckhauser (2002) who have access to auction and feedback data from eBay report that buyers commented on sellers 52.1 per cent of the time and sellers on buyers 60.6 per cent of the time.

A feedback is a "positive," “neutral," or "negative” rating accompanied by a textual comment. When a rating is left, it is immediately observable to the counterpart and to the community. The ratings a user receives from distinct other members are used to calculate his "feedback score.” A positive rating from a trading partner who has not rated this user before increases the user's feedback score by one point, a negative decreases it by one point, and a neutral leaves it unchanged. If a user interacts repeatedly with the same trading partner and receives more than one rating from her, the balance of these ratings is calculated. If the balance is positive, the user's score increases by just one point, if it is negative, the score decreases by just one point. Thus, each member cannot affect another member's feedback score by more than one point.

The "feedback score" is the most prominent indicator of a member's reputation on eBay and shown in parentheses next to his user ID wherever it is displayed on eBay, no matter in what context. When the user acts as a seller - that is, on every item page -, in addition to his feedback score, the percentage of positive feedback amongst all positive and negative ratings he has received is reported, again considering only ratings from distinct other members. More detailed information on any user, seller or buyer, as well as several summary statistics are 
available in the "feedback profile" that eBay provides for every member. Included there is a record of all feedback, with textual comments, that the user has ever received from and himself left on other members. ${ }^{14}$ The ratings in a feedback profile can be sorted so that only ratings received as a seller or ratings received as a buyer are displayed. ${ }^{15}$

\subsection{Last minute feedback?}

With the reciprocity of the system, a detail of crucial importance is the "ending rule" of the period in which trading partners can post their feedback (below "feedback period”). When retaliation is possible it is important whether this period is of fixed or stochastic length. We have argued that dissatisfied participants may be (rightly) concerned that if they post a justified negative feedback the trading partner could retaliate with a non-justified negative. This could only be avoided if it was possible to leave a rating in the "last minute" of a deterministic feedback period. Then, the trading partner will not have time to retaliate.

Such a strategic situation closely resembles that leading to "last minute bidding" in English auctions with fixed ending time (Roth and Ockenfels, 2002). In both cases a "last minute action” is exploited in order to prevent opponents from reacting. However, if one were to consider mechanisms without fixed ending times, agents in an auction would still prefer placing a bid to abstaining. ${ }^{16}$ On the contrary, giving a negative feedback becomes less attractive because of the fear of retaliation. Hence, if truthful reporting is a welfare concern, the presence of a last minute is desirable in the context of feedback.

While eBay only guarantees that feedback can be left within 90 days after an item is sold, it seems to be a widespread perception that feedback cannot be left after this 90-day period. Examining our data base and again the structure of the eBay platform we found, instead, that feedback can in fact be left as long as the auction details are available. Moreover, if a first feedback is left, the party that received the rating has the opportunity to reply for at least another 90 days. This is because whenever feedback is left for a particular transaction, the rating is recorded in the feedback profiles of the member that leaves and of the member that receives the rating. From there the rating is linked to the item details for another 90 days - not after the end of the auction, but starting with the time the first feedback has been

\footnotetext{
${ }^{14}$ Members can make their feedback profile "private”. In that case, other users can see only summary statistics of the feedback record. However, while his feedback profile is private, a user is prohibited from selling on eBay.

${ }^{15}$ On the German site, for example, users have the additional option to display only ratings from the past month, or the past 6 or 12 months. For these periods, users can then choose to display feedback by type, i.e., only positive, only neutral, or only negative - or only withdrawn - ratings. This feature is not is not available on U.S. eBay; it is on other sites.
} 
left. The eBay system is built in a way so that therefore the details will be available for at least another 90 days. As a result, the receiver of a first feedback will always have time to reply to this rating.

In light of the considerations about feedback retaliation and truthful reporting, it is surprising that the end of the feedback period is stochastic on eBay, and in fact automatically extended after the first rating. That is, the current real ending rule of the feedback period on eBay is similar to the one of Amazon for auctions. ${ }^{17}$ With this structure, the eBay feedback mechanism in principle discourages truthful negative ratings by the potential first feedback giver, by giving the opponent enough time to retaliate.

\subsection{Mutual feedback withdrawal}

Another important feature of the mechanism in this context is the possibility to mutually withdraw feedback. Once recorded, a rating cannot be unilaterally removed. However, what probably not all users have noticed, feedback can be withdrawn if both parties agree to. ${ }^{18}$ Because of this option, the receiver of a first negative feedback has an incentive to strategically reply with a negative feedback in order to induce her trading partner to agree to a mutual withdrawal of ratings. She might consider doing this even if she is in fact happy with the behavior of her trading partner in the underlying transaction. If both trading partners then agree on a feedback withdrawal, again, no negative feedback would be observed. If an eBay user is not fully aware of this fact, she might overestimate the informational content of feedback records. ${ }^{19}$

To summarize, key elements of the classic feedback mechanism are the following:

\footnotetext{
${ }^{16}$ For example, Amazon type auctions end only when no more bids are placed.

17 There, a "last minute" bid prolongs the auction period automatically. See http://www.amazon.com/gp/help/ customer/display.html? ie=UTF8\&nodeId=1161360 (September 2006).

${ }^{18}$ eBay states that "[a]fter both parties have agreed to withdraw the feedback, both parties will have their feedback scores adjusted at the same time...eBay will add a note to the feedback comment, saying that the feedback was mutually withdrawn...If you haven't left feedback for your trading partner and you go through the Mutual Feedback Withdrawal process, you will no longer be able to leave feedback for that transaction...Y You may only request Mutual Feedback Withdrawal once for every feedback left... Members may initiate a request to mutually withdraw feedback within 30 days of either person leaving feedback or within 90 days of the transaction end date, whichever is later.” Taken from http://pages.ebay.com/help/feedback/questions/mutualwithdrawal.html (September 2006).

19 Jin and Kato (2002) find in a field experiment that "at least some buyers" overestimate the informational content of feedback score and “drastically underestimate the risk of trading online." Likewise, Resnick, Zeckhauser, Swanson, and Lockwood (2004) question whether price premia, which they find, reflect a reputation equilibrium, and should in fact not be observed in the data.
} 
1. Feedback is immediately observable.

2. There is always a time window allowing a trading partner to react to a rating as long as he has not entered one yet.

3. Feedback can be withdrawn upon the mutual consent of both trading partners.

Figure 1 contains a state chart representing these key elements. Each circle in the graph represents a state and each arrow a transition from a state into another state or into itself. Such a transition happens in every instant of time. Towards a description of the state chart, we enter the feedback game from the left. We are in the state in which nobody has left feedback so that it can still be left by both. In the next instant of time, either no one rates and the feedback period is not over, or only one of the two parties rates, or both rate each other simultaneously, or the feedback period is over. Depending on the actions of the players we transit into another state.

The last (gray shaded) state is always the payoff state. Payoffs are to be understood as expected payoffs from future transactions on eBay, conditional upon the feedback outcome. Depending on the history, either no feedback has been left, or one or two ratings have been left without being withdrawn - the usual case -, or ratings have been left and were withdrawn thereafter. $^{20}$

The dashed part of the graph represent the misperception of the existence of a last minute of the feedback period which was discussed above. To be more specific, the misperception is that after 90 days there is a transition into a "last minute" state in which the trading partner cannot react to a rating. Most importantly, the chart (without the dashed part) shows that once a first feedback is left, in fact, the trading partner always has the opportunity to react with a second feedback.

\section{The Recent Changes}

As already mentioned, the eBay feedback mechanism changed substantially in May 2007. Since then buyers can, in addition to the "classic" feedback, leave detailed ratings on a seller regarding four different criteria: Item as described, communication, shipping time, and shipping and handling charges. A buyer can award the seller one to five stars on each of these

\footnotetext{
${ }^{20}$ For ease of the exposition, we make the simplifying assumption that we can always enter the feedback withdrawal process after at least one feedback has been left. In reality, every player may initiate this only once, see footnote 20 for details. Note that only a subset of the users on eBay is likely to be aware of the possibility of withdrawal.
} 
aspects. Detailed seller ratings are optional, and it is left to the buyer's discretion whether she wants to rate the buyer in any of these areas. ${ }^{21}$ If a buyer wants to leave detailed ratings, she must do so at the same time as she leaves the classic "overall” feedback with textual comment. Classic feedback can be left without providing detailed ratings, but not the other way around. Concerning their substance, however, overall feedback and detailed ratings need not be connected in any way. For example, the buyer could leave a positive classic feedback, and at the same time give only one star on each of the four criteria.

The most important characteristic of detailed seller ratings is anonymity. For each criterion, only the average of all ratings is given, and a seller must receive at least ten ratings before the average is reported in his feedback profile. EBay stresses that "sellers will not be able to see the detailed seller ratings you've given them,"22 and when actually leaving detailed ratings, buyers are notified again that "sellers will not see your individual ratings" and that "only the average of all buyer ratings can be seen by the seller." In other words, buyers are assured that, with the new detailed seller ratings, they are safe from retaliation.

As with the classic feedback score that any buyer can affect by only one point, if a buyer leaves detailed ratings on the same seller for different transactions, only the average of her ratings enter the seller's statistic for that criterion. In contrast to the classic feedback score, averages for detailed ratings will be calculated over the preceding 12 months only. ${ }^{23}$

At the same time when eBay introduced detailed seller ratings, it also made some minor changes to the feedback system, namely, to the way in which "classic" ratings are displayed. Before, apart from the auction number, only the rating - "positive," "neutral," or "negative” -, the textual comment, the feedback giver and the date and time when the rating was left were displayed. The auction number linked to the item details for 90 days after the rating had been left and users had to follow that link to learn more about the transaction. Today, in addition to this information, with feedback from the preceding 90 days on transactions where the member acted as the seller, the title of the item and the price for which it was sold are also reported in his feedback profile. Potential buyers can thus see at a glance from what kind of item a recent rating stems, and whether it was given on a high value or on a low value transaction.

\footnotetext{
${ }^{21}$ Buyers cannot rate on "shipping time” and "shipping and handling charges" in motor vehicle categories.

22 http://pages.ebay.com/help/feedback/detailed-seller-ratings.html (September 2007)

${ }^{23}$ Note that there are (rare) situations in which the rating can be inferred. This is because the average rating is presented accurate to a tenth of a star. For example, if a user has an average rating of 5 stars from 10 ratings and receives an 11th rating he can infer it if it changes his average rating, i.e. if it is at most 4 stars. However, in typical situations this will not be possible as the typical rating is between 3 and 5 stars and the average will be calculated from substantially more than 10 ratings. Moreover, for this to be possible the user needs to watch in real time how his average rating changes in order to associate the rating with a transaction through the classic rating that is left at the same time and then shown explicitly in the feedback record.
} 
Empirically, on eBay, the overwhelming share of classic feedback is positive. Resnick and Zeckhauser (2002) report that, in their data, ratings left by sellers and buyers were positive in 99.1 and 98.1 per cent of the cases, respectively. From another point of view, the average seller's share of negative ratings in the study by Cabral and Hortaçsu (2006) is 0.9 per cent of all comments. Furthermore, there is a high correlation between first and second ratings. This has been interpreted as evidence for reciprocity and retaliation. ${ }^{24}$ It will be interesting to see in the future how buyers evaluate sellers under the new, non-reciprocal and anonymous regime. The next section provides first empirical results on this question.

\section{Empirical Results}

The data we use were collected in several steps. First, in May 2007, we have obtained the usernames of, respectively, 3000 users that were selling in the five categories listed in Table $2 .^{25}$ Then, on the $1^{\text {st }}$ of June, July, August, and September, we have collected their feedback overview pages, one per user. This leaves us with detailed information on user characteristics such as the overall percentage positive marks received over their life as an eBay user and most importantly, information on ratings received in the 5 months prior to the change and in the first 4 months after the change. ${ }^{26}$ From these raw data we construct percentages for the classic ratings in order to compare them to the average number of stars obtained in the new part of the feedback mechanism.

Table 3 contains summary statistics. They are reported for our core sample consisting of users for which detailed ratings are available. ${ }^{27}$ They show that there are both some big players with large feedback records but also smaller ones. The distribution of feedback scores is highly skewed with a mean of 1998 and a median of 616. About 29 per cent of these sellers are power sellers. Interestingly, in the first 4 months after the introduction of the new system a

\footnotetext{
${ }^{24}$ See, for example, Resnick, Kuwabara, Zeckhauser, and Friedman (2000), Resnick and Zeckhauser (2002), Bajari and Hortaçsu (2004), Cabral and Hortaçsu (2006), and Chwelos and Dhar (2005). If quantitatively important, both forms of strategic behavior reduce the informational content of the reputation index and in particular bias it towards positive evaluations of the transaction. This point is also made by Dellarocas and Wood (forthcoming) who estimate that only about 86 per cent of eBay users are actually happy with the underlying transaction.

${ }^{25} 59$ users have listed an item in two categories and 1 user in 3 categories. These multiple listings were treated as multiple observations in our data set.

${ }^{26}$ In particular, we use the information on the number of ratings, by type, that were received within the last month, respectively. They are added over the 4 waves. For the ratings that were received in the last 5 months prior to the change we use the number of ratings received in the "past 6 months" that was published on June 1 and substract the number of ratings received in the "last month."

${ }^{27}$ Table 4 shows percentiles of the distribution of feedback scores by availability of summary statistics for detailed ratings. It reflects that these are only available if at least 10 such ratings have been left, i.e. for the more active sellers with higher feedback scores.
} 
seller in our sample received 317 classic ratings and 163 detailed ratings on average. This reflects the fact that detailed ratings can only be received once users act as sellers.

Our data confirm the well known empirical finding that the overwhelming share of classic ratings is positive. Interestingly, this share is declining once we compare the 5 months prior to the introduction of the new rating possibilities to the first 4 months after the system has been put in place. This decline is small but significant with a $p$-value of 0 . One interpretation of this is that the recent changes have motivated some users to expose themselves to the risk of retaliation. It is an open question whether this can be reconceiled with rational behavior.

Figure 2 contains a box plot for the average number of stars received by the users in our sample. Overall, these ratings are very positive. In part this could be driven by the fact that detailed ratings are only available for active players, namely those who have received at least 10 detailed ratings in their role as a seller over the first four months the new system was in place. As we have started with 3,000 sellers in each of 5 categories this is only the case for 3,700 out of 15,000 sellers. Still, it is interesting to see that the typical seller receives many ratings that are not of the best type, 5 stars. This is in contrast to the finding that almost all classic ratings are of the best type, positive, and is well consistent with the arguments that have been made in Section 2 and 3.

Table 5 contains, by category and percentage negative ratings received in the same period, sample means of the average number of stars received by the user. It illustrates the dependence between the two measures and shows that even for users who have received less than 95 per cent positive feedbacks the detailed ratings are very good, e.g. on average between “accurate” and "very accurate” for the item description..

Finally, Table 6 contains results from a regression of the average star rating on a rich set of user characteristics. It illustrates in particular that the number of stars depends positively on the number of detailed ratings received, the percentage positive feedbacks received and the overall percentage positive feedbacks. It depends negatively on the feedback score and is smaller for power sellers.

We conclude from these first empirical results that the rating possibilities that were recently added to the feedback mechanism tend to add valuable information. In particular, about 99 per cent of classic ratings are in the best category, positive, this seems not to be the case for the detailed ratings. ${ }^{28}$ In our previous discussion we have related this to the fact that

\footnotetext{
${ }^{28}$ Figure 2 shows that the third quartile of the average rating per user is well below 5 stars.
} 
here, the fear of a retaliatory feedback does not play a role as the type of rating cannot be inferred by the seller.

\section{Conclusions}

In this paper we have investigated the institutional details of both the classic part of eBay's reputation mechanism and its newly added features. It is well known that the former allows for the immediate observation of feedbacks given by the trading partners. Therefore, the timing of feedbacks and their type may be guided by strategic considerations. Leaving a truthful negative feedback is a risky endeavor because it may be retaliated untruthfully, and purely for strategic reasons. Conversely, the existence of a deterministic last minute of the feedback period would allow for negative first feedback giving without retaliation. However, closer scrutiny of eBay's reputation mechanism reveals that to the contrary to the existence of such a last minute a trading partner has always enough time to react to a first rating. This implies that a negative first feedback can never be given without the fear of retaliation. One aim of this paper was to emphasize this point.

A direct consequence of this institutional design is that a first feedback giver, if behaving opportunistically towards establishing a good feedback record, may not give a negative feedback even if it were justified. Instead, she might wait for her partner to give the first feedback. If both wait, no feedback is left at all. ${ }^{29}$ Conversely, leaving a positive feedback might be driven by expectations on feedback reciprocity which induces the trading partner to react with a positive mark.

For this reason, many studies have argued that direct inference from the classic ratings on the true performance of the participating agents should be handled with care. Importantly, this does not apply to the recently added rating possibilities for buyers rating sellers as they ensure anonymity. ${ }^{30}$ The difference between the two has been at the center of the empirical analysis that has bee presented in Section 4 of this paper. One important difference is that whereas about 99 per cent of the classic ratings are given in the best category, positive, this is not the case in the new system.

In addition to the changes that were recently made there may be scope for further improvements of the classic part of eBay's feedback mechanism using easy-to-implement measures. In particular, our analysis suggests that to reduce concerns for retaliation and to

\footnotetext{
${ }^{29}$ Dellarocas and Wood (forthcoming) investigate the consequences of non-random missing feedbacks on feedback scores. They find that dissatisfied traders are more likely not to give a feedback.

${ }^{30}$ An additional advantage of these features is that separate reputation measures with respect to four key criteria are calculated so that more detailed information is communicated to the community.
} 
foster expression of deserved dissatisfaction, the revelation of information should be delayed. Most importantly, feedback should only be revealed to the trading partners and thus, the public, if no more feedback can be left. ${ }^{31}$ This could alternatively be done after a fixed period, or after both trading partners have given their feedback. A direct consequence could be that less users might be willing to leave a first (positive) rating because they cannot hope any more to thereby induce their trading partner to leave a rating in return. However, this might be a desired effect as, on average, the rating would closer to the true satisfaction of the user who left it. Another important point is that this change alone would potentially make things even worse as long as the mechanism would still allow for the mutual withdrawal of feedback. We therefore advocate to also remove this option. Otherwise, it tends to remain a dominant strategy to always retaliate negative feedbacks in order to be able to renegotiate after ratings have been revealed.

Finally, it can be argued that the performance of buyers, if asked to pay first, is subject to little uncertainty. Either the full payment arrives in time which is verifiable by the seller, or it does not. Then, opportunism on the buyer's side does not play a role. To the contrary, sellers can misbehave on a variety of aspects of their performance. Therefore, it may be worthwhile to limit feedback to buyers rating sellers as in Amazon auctions. ${ }^{32}$ Such a change of rules is likely to induce less feedback giving. However, by removing potentially very substantive biases, it should increase the informational content of feedback records and therefore lead to an unequivocal improvement in the allocation decisions taken in this increasingly important market.

\footnotetext{
${ }^{31}$ That is, both whether a feedback was left and the type of feedback should both be concealed to opponents. This is somewhat different from the suggestion of concealing only the type of feedback left which has been made in independent work by Reichling (2004).

${ }^{32}$ This is also suitable for e-procurement platforms. See Dini and Spagnolo (2006); Dellarocas, Dini, and Spagnolo (2006) for further details.
} 


\section{Tables and Figures}

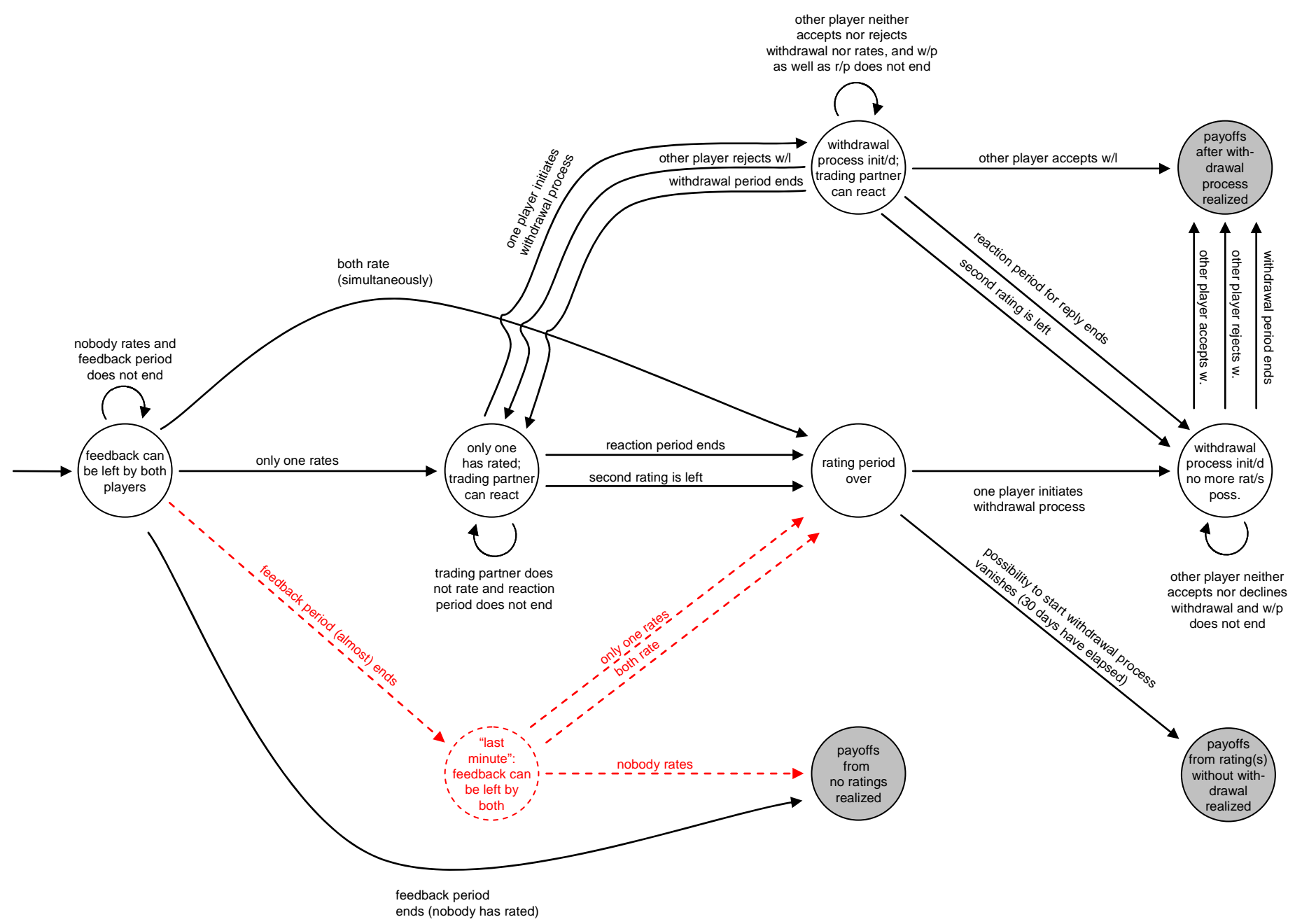

Figure 1: State Chart 


\begin{tabular}{|c|c|c|c|c|c|}
\hline & $1 \mathrm{star}$ & 2 stars & 3 stars & 4 stars & 5 stars \\
\hline How accurate was the item description? & Very inaccurate & Inaccurate & Neither inaccurate nor accurate & Accurate & Very accurate \\
\hline How satisfied were you with the seller's communication? & Very unsatisfied & Unsatisfied & Neither unsatisfied nor satisfied & Satisfied & Very satisfied \\
\hline How quickly did the seller ship the item? & Very slowly & Slowly & Neither slowly nor quickly & Quickly & Very quickly \\
\hline How reasonable were the shipping and handling charges? & Very unreasonable & Unreasonable & Neither unreasonable nor reasonable & Reasonable & Very reasonable \\
\hline
\end{tabular}

Notes: In the empirical analysis we multiply the numbers of stars by 100 .

Table 1: Meaning of Stars

Home $>$ All Categories $>$ Computers \& Networking $>$ Laptops, Notebooks

Home $>$ All Categories $>$ Consumer Electronics $>$ Apple iPod, MP3 Players

Home $>$ All Categories $>$ Toys \& Hobbies $>$ Model RR, Trains

Home $>$ All Categories $>$ Collectibles $>$ Trading Cards

Home $>$ All Categories $>$ Home \& Garden $>$ Food \& Wine

Notes: These categories are from the U.S. eBay system.

Table 2: Categories 


\begin{tabular}{|c|c|c|c|c|c|}
\hline variable & obs. & mean & std. & $\min$. & $\max$. \\
\hline duration membership in years & 3704 & 4.708935 & 2.79298 & .2662641 & 11.35455 \\
\hline member is powerseller & 3704 & .287257 & .4525436 & 0 & 1 \\
\hline member has "About Me" page & 3704 & .2062635 & .4046765 & 0 & 1 \\
\hline member has store & 3704 & .2888769 & .4533018 & 0 & 1 \\
\hline received ratings $1 / 12 / 2006-30 / 4 / 2007$ & 3704 & 424.5192 & 1279.438 & 0 & 29913 \\
\hline Positive & 3704 & 420.169 & 1258 & 0 & 29371 \\
\hline Neutral & 3704 & 2.464633 & 15.57879 & 0 & 565 \\
\hline Negative & 3704 & 1.885529 & 14.9093 & 0 & 599 \\
\hline neutral or negative & 3704 & 4.350162 & 29.56397 & 0 & 1164 \\
\hline \multicolumn{6}{|l|}{ percentage ratings $1 / 12 / 2006-30 / 4 / 2007$} \\
\hline positive & 3600 & .9933102 & .0181821 & .5 & 1 \\
\hline neutral & 3600 & .0037267 & .0117517 & 0 & .3333333 \\
\hline negative & 3600 & .0029631 & .0124911 & 0 & .5 \\
\hline neutral or negative & 3600 & .0066898 & .0181821 & 0 & .5 \\
\hline received ratings $1 / 5 / 2007-31 / 8 / 2007$ & 3704 & 317.0221 & 805.7485 & 9 & 16376 \\
\hline positive & 3704 & 312.8688 & 790.7764 & 6 & 16099 \\
\hline neutral & 3704 & 2.276188 & 10.59245 & 0 & 189 \\
\hline negative & 3704 & 1.87716 & 9.705481 & 0 & 229 \\
\hline neutral or negative & 3704 & 4.153348 & 19.56509 & 0 & 390 \\
\hline \multicolumn{6}{|l|}{ percentage ratings $1 / 5 / 2007-31 / 8 / 2007 \mid$} \\
\hline positive & 3704 & .9882549 & .0294073 & .4285714 & 1 \\
\hline neutral & 3704 & .0056498 & .0122027 & 0 & .2142857 \\
\hline negative & 3704 & .0060953 & .0221143 & 0 & .4871795 \\
\hline neutral or negative & 3704 & .0117451 & .0294073 & 0 & .5714286 \\
\hline \multicolumn{6}{|l|}{ detailed ratings $1 / 5 / 2007-31 / 8 / 2007$ (from 100 to 500 ) } \\
\hline item description & 3697 & 478.5718 & 17.21757 & 240 & 500 \\
\hline communication & 3686 & 472.9246 & 21.29634 & 260 & 500 \\
\hline shipping time & 3691 & 467.2446 & 27.07251 & 280 & 500 \\
\hline shipping charges & 3683 & 458.189 & 21.84099 & 330 & 500 \\
\hline average number of detailed ratings $1 / 5 / 2007-31 / 8 / 2007$ & 3704 & 162.6302 & 492.9356 & 10 & 13955.5 \\
\hline item description & 3697 & 163.6024 & 495.4557 & 10 & 14016 \\
\hline communication & 3686 & 162.9954 & 492.5329 & 10 & 13875 \\
\hline shipping time & 3691 & 163.2647 & 494.0045 & 10 & 13990 \\
\hline shipping charges & 3683 & 163.0975 & 493.3157 & 10 & 13941 \\
\hline member feedback score & 3704 & 1998.008 & 5647.452 & 1 & 148980 \\
\hline overall percentage positives & 3704 & 99.47929 & 1.500672 & 48.6 & 100 \\
\hline
\end{tabular}

Notes: The observational unit is a user who has offered a good in one of the categories listed in Table 2 and for whom detailed ratings are available. Received ratings are "traditional" ratings which are either positive, neutral or negative. These ratings are not anonymous and are directly observable to the trading partner. Detailed ratings are the ratings that can now be left additionally to the traditional ratings. Here, 1 to 5 stars can be left, respectively. We multiply the average number of stars received, per user, by 100 . The number of observations differs across detailed and traditional ratings because the detailed rating is optional and only possible if a traditional rating is left. This explains why the number of detailed ratings differs from the number of received traditional ratings. The member feedback score is the number of unique users who left a net positive rating minus the number of unique users who left a net negative rating. The overall percentage negative ratings is calculated from all ratings the user has received.

\section{Table 3: Summary Statistics}




\begin{tabular}{lrrrrrrrrr}
\hline \hline & \multicolumn{10}{c}{ percentile } \\
detailed rating & 1 & 5 & 10 & 25 & 50 & 75 & 90 & 95 & 99 \\
\hline no & 0 & 1 & 3 & 15 & 60 & 189 & 446.5 & 705 & 1650 \\
yes & 26 & 59 & 99 & 229 & 616 & 1646 & 4199 & 7612 & 24714 \\
\hline \hline
\end{tabular}

Table 4: Percentiles of the Distribution of feedback scores by availability of detailed ratings

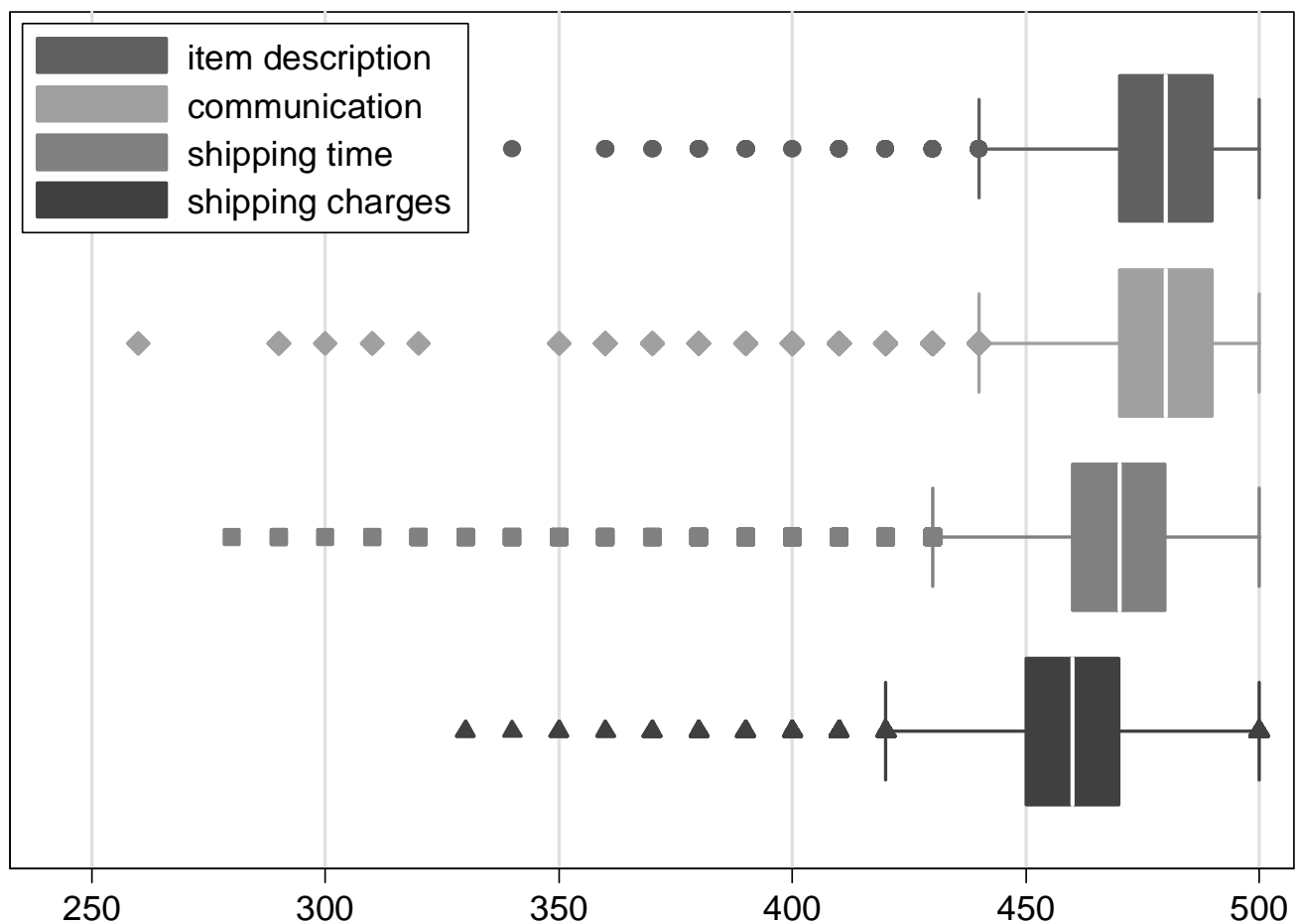

Notes: The horizontal axis is the average number of stars for a given user multiplied by 100 . The box is bounded on the left by the first quartile and on the right by the third quartile. The observations outside the two whisker are considered to be outliers and are reported. The observation on the very left is the lowest observed value, respectively.

Figure 2: Box Plot for Detailed Ratings

\begin{tabular}{|c|c|c|c|c|c|}
\hline & obs. & $\begin{array}{c}\text { item } \\
\text { description }\end{array}$ & $\begin{array}{l}\text { communi- } \\
\text { cation }\end{array}$ & $\begin{array}{l}\text { shipping } \\
\text { time }\end{array}$ & $\begin{array}{l}\text { shipping } \\
\text { charges }\end{array}$ \\
\hline & 3669 & 478.624 & 472.976 & 467.291 & 458.237 \\
\hline 100 per cent of feedbacks positive & 1919 & 483.715 & 480.130 & 475.393 & 464.914 \\
\hline at most 95 per cent feedbacks positive & 185 & 446.703 & 426.595 & 416.054 & 425.676 \\
\hline
\end{tabular}

Notes: This table shows, in the colums, respectively, the condition on the percentage positive feedbacks received last month, the number of observations and the average rating received across users. The first column is the conditioning set. The average number of stars is muliplied by 100. For example, the number 483.715 means that among all users who received only positive ratings in the last month the average score for the item desciption was 4,84 . Reported for users for which all four summary statistics are reported.

\section{Table 5: Detailed Ratings}




\begin{tabular}{|c|c|c|c|c|}
\hline & $\begin{array}{c}\text { item } \\
\text { description }\end{array}$ & $\begin{array}{l}\text { communi- } \\
\text { cation }\end{array}$ & $\begin{array}{l}\text { shipping } \\
\text { time }\end{array}$ & $\begin{array}{l}\text { shipping } \\
\text { charges }\end{array}$ \\
\hline \multirow[t]{2}{*}{ category notebooks } & -5.803 & -6.069 & -2.855 & -8.883 \\
\hline & $(7.75)^{\star \star}$ & $(7.21)^{\star \star}$ & $(2.37)^{\star}$ & $(8.65)^{\star \star}$ \\
\hline \multirow[t]{2}{*}{ category mp3 players } & -6.691 & -5.708 & -3.592 & -10.939 \\
\hline & $(7.93)^{\star \star}$ & $(6.01)^{\star \star}$ & $(2.65)^{\star \star}$ & $(9.44)^{\star \star}$ \\
\hline \multirow[t]{2}{*}{ category model rr trains } & -3.310 & -1.275 & -2.140 & -0.061 \\
\hline & $(4.92)^{\star \star}$ & $(1.69)$ & $(1.98)^{\star}$ & $(0.07)$ \\
\hline \multirow[t]{2}{*}{ category trading cards } & -0.414 & -1.559 & -4.749 & -0.109 \\
\hline & $(0.68)$ & $(2.28)^{\star}$ & $(4.85)^{\star \star}$ & $(0.13)$ \\
\hline \multirow[t]{2}{*}{ log of mean number of detailed ratings } & 1.287 & 1.454 & 2.567 & 0.071 \\
\hline & $(4.18)^{\star \star}$ & $(4.20)^{\star \star}$ & $(5.18)^{\star \star}$ & $(0.17)$ \\
\hline \multirow[t]{2}{*}{ percentage neutral ratings } & -391.187 & -509.203 & -697.092 & -421.991 \\
\hline & $(18.71)^{\star \star}$ & $(21.69)^{\star \star}$ & $(20.64)^{\star \star}$ & $(14.73)^{\star \star}$ \\
\hline \multirow[t]{2}{*}{ percentage negative ratings } & -40.905 & -204.224 & -192.535 & -4.601 \\
\hline & $(3.60)^{\star \star}$ & $(16.00)^{\star \star}$ & $(10.02)^{\star \star}$ & $(0.30)$ \\
\hline \multirow[t]{2}{*}{ log feedback score } & -0.710 & -1.661 & -1.970 & -0.586 \\
\hline & $(2.44)^{*}$ & $(5.09)^{\star \star}$ & $(4.22)^{\star \star}$ & $(1.47)$ \\
\hline \multirow[t]{2}{*}{ overall percentage positive feedbacks } & 4.816 & 4.825 & 4.738 & 4.651 \\
\hline & $(410.77)^{\star \star}$ & $(365.79)^{\star \star}$ & $(251.89)^{\star \star}$ & $(289.25)^{\star \star}$ \\
\hline \multirow[t]{2}{*}{ duration membership } & 0.669 & 0.811 & 1.292 & 0.852 \\
\hline & $(6.26)^{\star \star}$ & $(6.75)^{\star \star}$ & $(7.52)^{\star \star}$ & $(5.81)^{\star \star}$ \\
\hline \multirow[t]{2}{*}{ member is power seller } & -0.384 & -0.985 & -0.996 & -2.261 \\
\hline & $(0.62)$ & $(1.43)$ & $(1.01)$ & $(2.68)^{\star \star}$ \\
\hline \multirow[t]{2}{*}{ member has "about me" page } & 0.223 & 1.852 & 0.842 & 1.585 \\
\hline & $(0.37)$ & $(2.72)^{\star \star}$ & $(0.87)$ & $(1.91)$ \\
\hline \multirow[t]{2}{*}{ member has store } & 1.637 & 0.244 & -0.883 & 0.390 \\
\hline & $(2.84)^{\star \star}$ & $(0.38)$ & $(0.95)$ & $(0.49)$ \\
\hline obs. & 3697 & 3686 & 3691 & 3683 \\
\hline R-squared & 1.00 & 1.00 & 1.00 & 1.00 \\
\hline
\end{tabular}

Notes: The columns contain coefficient estimates and respective standard errors that were obtaines from a regression of the respective dependendent variable on the covariates listes above. The dependendent variable is the average number of stars received multiplied by 100 .

Table 6: Regression Results 


\section{References}

BAJARI, P., AND A. HoRtaçSU (2003): "The Winner's Curse, Reserve Prices, and Endogenous Entry: Empirical Insights from eBay Auctions," RAND Journal of Economics, 34(2), 329-355.

--- (2004): “Economic Insights from Internet Auctions,” Journal of Economic Literature, 42(2), 457-489.

CABral, L. M. B., AND A. HortaçSu (2006): “The Dynamics of Seller Reputation: Theory and Evidence from eBay,” Mimeograph.

Chwelos, P., AND T. DhaR (2005): "Caveat Emptor: Differences in Online Reputation Mechanisms,” Mimeograph.

Dellarocas, C. (2005): “Reputation Mechanisms," Working Paper, University of Maryland.

Dellarocas, C., F. Dini, AND G. Spagnolo (2006): "Designing Feedback Mechanisms for e-Procurement Platforms," in Handbook of Procurement, ed. by N. Dimitri, G. Piga, and G. Spagnolo, chap. 18. Cambridge University Press.

Dellarocas, C., AND C. A. WoOd (forthcoming): "The Sound of Silence in Online Feedback: Estimating Trading Risks in the Presence of Reporting Bias," Management Science.

Dini, F., AND G. Spagnolo (2006): "Reputation Mechanisms and Electronic Markets: Economic Issues and Proposals for Public Procurement," in Challenges in Public Procurement: an International Perspective, ed. by K. V. Thai, A. Araujo, R. Y. Carter, G. Callender, D. Drabkin, R. Grimm, K. R. Ejlskov Jensen, R. E. Lloyd, C. P. McCue, and J. Telgen. Academic Press.

FEHR, E., AND K. SCHMidT (1999): “A Theory of Fairness, Competition and Cooperation,” Quarterly Journal of Economics, 114(3), 817-868.

Houser, D., AND J. WoOders (2006): "Reputation in Auctions: Theory, and Evidence from eBay,” Journal of Economics and Management Strategy, 15(2), 353-370.

Jin, G. Z., AND A. Kato (2002): "Blind Trust Online: Experimental Evidence from Baseball Cards,” Working Paper, University of Maryland.

LipPeRT, S., AND G. SPAgnOlO (2006): "Networks of Relation, Word-of-Mouth Communication, and Social Capital,” Mimeograph.

Livingston, J. A., AND W. N. Evans (2004): "Do Bidders in Internet Auctions Trust Sellers? A Structural Model of Bidder Behavior on eBay,” Working Paper, Bentley College.

Lucking-Reiley, D., D. Bryan, N. Prasad, and D. Reeves (2007): "Pennies from eBay: the Determinants of Price in Online Auctions," Journal of Industrial Economics, 55(2), 223-233.

Mailath, G. J., And L. SAmuelson (2006): Repeated Games and Reputations: Long-Run Relationships. Oxford University Press.

McDonald, C. G., AND V.C. Slawson (2002): "Reputation in an Internet Auction Market,” Economic Inquiry, 40(3), 633-650. 
MelniK, M. I., AND J. Alm (2002): "Does a Seller's Reputation Matter? Evidence from eBay Auctions,” Journal of Industrial Economics, 50(3), 337-349.

Reichling, F. (2004): "Effects of Reputation Mechanisms on Fraud Prevention in eBay Auctions,” Thesis, Stanford University.

Resnick, P., K. Kuwabara, R. Zeckhauser, and E. Friedman (2000): "Reputation systems," Communications of the ACM, 43(12), 45-48.

Resnick, P., AND R. ZeCKhauser (2002): "Trust Among Strangers in Internet Transactions: Empirical Analysis of eBay's Reputation System. The Economics of the Internet and E-Commerce.," in Advances in Applied Microeconomics, ed. by M. R. Baye, vol. 11, Amsterdam. Elsevier Science.

Resnick, P., R. Zeckhauser, J. Swanson, And K. Lockwood (2004): "The Value of Reputation on eBay: A Controlled Experiment,” Working Paper, Harvard Kennedy School of Business.

Roth, A. E., AND A. OcKenfels (2002): "Last-Minute Bidding and the Rules for Ending Second-Price Auctions: Evidence from eBay and Amazon on the Internet," American Economic Review, 92(4), 1093-1103. 